\title{
Semantic satiation in healthy young and older adults
}

\author{
DAVID A. BALOTA \\ Washington University, St. Louis, Missouri \\ and \\ SHEILA BLACK \\ University of Alabama, Tuscaloosa, Alabama
}

\begin{abstract}
In four experiments, semantic satiation was investigated in young and old adults. In the first two experiments, subjects were repeatedly presented a word (e.g., DOG) and then were presented a pair of words (e.g., DOG-CAT or DOG-CHAIR) for a relatedness decision. The results of both experiments indicated that for the young adults, the relatedness effect (the difference between response latency on related and unrelated trials) decreased as a function of the number of times the satiated word was repeated, whereas for the older adults, there was no evidence of a decrease in the relatedness effect across repetitions of the satiated word. In the third experiment, we investigated whether phonological codes are also susceptible to satiation. This experiment was similar to the first two experiments with the exception that subjects made rhyme decisions (SAME-CLAIM vs. SAME-DIME) instead of semantic relatedness decisions. The results of this experiment did not yield any evidence of satiation for either the young adults or the older adults. The final experiment eliminated a simple decrease in attentional alertness or fatigue account of the semantic satiation effects found in the first two experiments. In this experiment, the repeated word was always unrelated to the pair of words presented for the relatedness decision. The results of this experiment did not yield any evidence of semantic satiation for either the young or the older adults. The discussion focuses on the mechanisms underlying semantic satiation and the implications of age-related changes in these mechanisms.
\end{abstract}

One of the hallmarks of the cognitive processing system is that the repetition of a stimulus facilitates the subsequent processing of that stimulus. In this light, it is intriguing that massed excessive exposure to a stimulus can actually inhibit subsequent processing of that stimulus, through satiation or habituation. Such a mechanism should have considerable evolutionary significance in that it would serve to bias the attentional system to further process new and changing (information laden) stimuli instead of old and/or static stimuli (MacKay, 1990). The focus of the present series of experiments was to explore a type of habituation/satiation referred to as semantic satiation: the attenuation in the meaningfulness of a word that occurs as a result of excessive exposure to that word

In the present series of experiments, we had two major goals. First, we attempted to extend and further explore recent observations of semantic satiation. As will be discussed below, considerable controversy has surrounded

This work was supported by NIA Grants POl AGO3991 and ROI AG10193, and represents a totally collaborative effort. Portions of this research were presented at the 65 th annual meeting of the Midwestern Psychological Association. We thank Steven Paul, Renee Frederickson, Donald MacKay, Edward Merrill, and Daniel Spieler for helpful comments on an earlier version of this manuscript. Requests for reprints should be sent to D. A. Balota, Department of Psychology, Box 1125, Washington University, St. Louis, MO 63130 (e-mail: dbalota@artsci. wustl.edu). this phenomenon. Second, we sought to explore the possibility that there are age-related differences in sensitivity to semantic satiation. Given the available evidence concerning differences across age groups in related constructs such as habituation and attentional processing (e.g., Balota, Black, \& Cheney, 1992; Hartley, 1992; McDowd \& Filion, 1992; Warren \& Warren, 1966; Yin \& MacKay, 1992), one might expect the semantic satiation paradigm to be particularly sensitive to age-related differences in information processing. We shall now turn to a brief review of both of these issues.

\section{Semantic Satiation}

Interestingly, as early as the turn of this century, reports suggested that words become less meaningful when repeated excessively (Bassett \& Warne, 1919). Since that time, investigators have used various paradigms to investigate semantic satiation. For example, by the late $1950 \mathrm{~s}$ and 1960 s, semantic satiation had been investigated via self-reports, association judgments, and word ratings (Esposito \& Pelton, 1971). Unfortunately, none of these paradigms yielded consistent evidence of semantic satiation, and therefore the interest in semantic satiation waned.

The appearance of spreading activation models (e.g., Collins \& Loftus, 1975) produced a renewed interest in the notion of semantic satiation, in part because these models provided a framework for interpreting satiation effects. According to the spreading activation framework, 
words are represented via nodes that are interconnected by associative pathways. When a conceptual node is activated either via stimulus presentation or via the direction of attention, activation presumably spreads from the activated node to nodes that represent associated words. This preactivation of related concepts in memory was consistent with the observation of semantic priming effects in both lexical decision and naming tasks (see Neely, 1991, for a review). Specifically, subjects are faster to recognize a target word (DOCTOR) when it follows a related prime (NURSE) than when it follows an unrelated prime (BUTTER). The notion is that when the first word is presented, it activates its underlying conceptual representation and activation spreads to related areas in the memory network. Hence, when a target is presented from one of those related areas of the memory network, subjects are faster to process this target because it has been preactivated.

The relevance of this spreading activation framework to semantic satiation appeared to be relatively straightforward and was motivated in part by the implicit parallel between spreading activation within an interconnected network and the communication between neurons in a neural network. The notion is that each time a word is presented, its underlying conceptual representation becomes activated. Eventually, via repeated exposure, the underlying conceptual node becomes fatigued in the same manner in which a neuron or neural ensemble might become fatigued via repeated stimulation. Thus, because of this fatigue due to repeated exposure, one should find an increased difficulty in accessing the meaning of the word-that is, semantic satiation.

Although the notion of semantic satiation nicely followed from the spreading activation framework, both Neely (1977a) and Cohene, Smith, and Klein (1978) failed to observe semantic satiation in a lexical decision task. In both of these studies, subjects repeated a word aloud for a varying number of repetitions and then made lexical decisions to a subsequently presented target word that was either related or unrelated to the earlier repeated word. The major finding from both of these studies was that there was no decrease in the relatedness effect as a function of repetition of words related or unrelated to the target words. Thus, it appeared that the activation from the repeated word did not decrease as a function of repetition. On the basis of this finding and a review of the available literature, Neely (1977a) concluded that there was little evidence for semantic satiation.

L. C. Smith (1984) argued that it was possible that the inconsistent results in the past satiation studies might have been due to a relatively insensitive dependent measure. Specifically, both Neely (1977a) and Cohene et al. (1978) used a lexical decision task, and there was accumulating evidence (e.g., Balota \& Chumbley, 1984; Forster, 1976) that this task is a poor measure of simple activation processes because of problems due to task-specific backward checking processes. The notion is that during the course of the experiment, subjects realize that when there is a relationship between primes and targets the tar- get must be a word. A prime can be related to another word, but it cannot be related to a nonword. Hence, subjects rely on the presence of a relationship between the prime and target to bias their decision, and this taskspecific strategy may have overridden any fragile satiation effects in these studies.

Because of the concern with task-specific strategies, L. C. Smith (1984) used a task that explicitly forced subjects to access semantic relationships but at the same time did not entail any task-specific strategies that might override satiation. In Smith's experiment, subjects pronounced a category word either 3 or 30 times and then a target word appeared. The subject's task was to decide whether the target word was or was not an exemplar of the category designated by the previous repeated word (e.g., FURNITURESOFA VS. FURNITURE-FROG). The results of this experiment indicated that subjects produced reliable satiation when performing the category verification task. Specifically, the difference between related and unrelated targets decreased between the 3-repetition condition and the 30-repetition condition. Thus, Smith concluded that semantic satiation can be observed when a more sensitive dependent measure is used. L.C. Smith and Klein (1990) more recently replicated this finding in a study in which subjects did not directly attend to the repeated word.

Although L. C. Smith's (1984; L. C. Smith \& Klein, 1990) studies provide evidence for satiation, we were interested in replicating and extending this work. Four issues were addressed in the present research. First, we included a manipulation of the strength of the semantic/associative relationship between the primes and targets (Experiments 1 and 2). Because high-strength word pairs should have more overlapping semantic features than should low-strength word pairs, we expected high-strength word pairs to be more susceptible to semantic satiation than low-strength word pairs. Second, we manipulated across experiments the extent to which subjects could predict the presentation of the target word. In the L. C. Smith experiments, subjects could predict the occurrence of the target word by counting the number of repetitions. Such prediction was minimized in the present Experiments 2,3 , and 4 , by randomly varying the number of repetitions. Third, we included three levels of repetition in the present experiments, instead of only the two levels of repetition included in the L.C. Smith studies. In this way, we could determine whether semantic satiation produces a linear or curvilinear pattern as a function of repetition. Fourth, we addressed the degree to which satiationtype effects also extend to other codes afforded by words. Specifically, in Experiment 3, subjects made rhyme decisions instead of semantic decisions to determine whether phonological codes are also susceptible to satiation-type effects.

In addition to the preceding explorations of the constraints of semantic satiation, in the present series of experiments we also explored possible age-related differences in this phenomenon. We shall now turn to a brief review of this literature. 


\section{Age-Related Differences in Habituation}

In each of the present experiments, we included both healthy young adults (mean age, approximately 20 years) and healthy older adults (mean age, approximately 70 years). We were motivated to include older adults in the present studies because evidence is already available which suggests that there may be age-related changes in satiation-type effects. Both Harrison and Isaac (1985) and McDowd and Filion (1992) have reported evidence that older adults are less susceptible to habituation-type effects than young adults. For example, McDowd and Filion found that older adults became habituated to a repeated tone at a significantly slower rate than did young adults.

In addition to the work on changes in habituation in young and older adults, there is also evidence of agerelated changes in a second satiation-type effect referred to as the verbal transformation effect (Warren \& Warren, 1966; Yin \& MacKay, 1992). In the verbal transformation paradigm, subjects listen to a clearly presented word repeated at approximately $1-\mathrm{sec}$ intervals. The results of such studies indicate that across repetitions, subjects begin to report changes in the identity of the repeated word. For example, if the repeated stimulus is the word PACE, and if it is continually repeated for $2-3 \mathrm{~min}$, subjects may begin to report hearing phonologically similar words such as FACE, SPACE, or PASTE (see MacKay, Wulf, Yin, \& Abrams, 1993). MacKay (1969) and MacKay et al. (1993) have interpreted this phenomenon within a satiation framework, in which the node corresponding to the repeated stimulus becomes satiated across repetitions, and hence nonsatiated but phonologically related lexical nodes become relatively more available across repetitions. Thus, the observation by Warren and Warren (1966) and Yin and MacKay (1992) of a reduced verbal transformation effect in older adults, compared with young adults, suggests that if one can obtain reliable satiation effects within the present experimental paradigm, one might expect older adults to be relatively less susceptible to such semantic satiation than young adults.

\section{EXPERIMENT 1}

In the first experiment, subjects were presented with two words on each trial. The to-be-satiated word was first repeated 2,12 , or 22 times and was then removed from the screen. Subjects were then presented with the satiated word along with a pairmate for a relatedness judgment. Semantic satiation would be indicated if the difference in response latencies between related and unrelated pairs decreased as a function of the repetition of the first word.

The major conditions of Experiment 1 are displayed in Table 1. Three major issues were addressed in this experiment. First, we attempted to determine whether the relatedness effect would decrease as a function of repetition for young adults, thereby replicating and extending L. C. Smith's studies. Second, we attempted to determine whether high-strength pairs would be more susceptible to semantic satiation than low-strength pairs. Third, we
Table 1

Example Set of Critical Conditions

\begin{tabular}{ccl}
\hline Relatedness & Repeated Word & Decision Pair \\
\hline & High-Strength Associates & \\
Related & ROYALTY & ROYALTY-QUEEN \\
Control & ROYALTY & ROYALTY-BOX \\
& Low-Strength Associates & \\
Related & ROYALTY & ROYALTY-DUKE \\
Control & ROYALTY & ROYALTY-PIG \\
\hline
\end{tabular}

Note-Table 1 displays the related and unrelated conditions as a function of strength of association. Other factors (e.g., age and repetition) are not included in this display. The repeated word was displayed 2, 12, or 22 times in Experiment 1, or, on the average, 4.5, 12.5, or 20.5 times in Experiments 2, 3, and 4.

attempted to determine whether older adults would be less susceptible to semantic satiation than young adults.

\section{Method}

Subjects. Thirty-six young and 36 older adults participated in this experiment. The mean age of the young adults was 21 , and their ages ranged between 18 and 38 years; the mean age for the older adults was 70 , and their ages ranged between 59 and 83 years. The young adults were student volunteers from undergraduate psychology classes. The older adults were community members from the Aging and Development Subject Pool. These individuals became part of the subject pool by responding to newspaper advertisements. The older adults received $\$ 5.00$ for participating in the experiment as reimbursement for travel expenses. All subjects were given Items 16 - 40 of the Vocabulary subtest of the Wechsler Adult Intelligence Scale (WAIS). The groups were virtually identical on the vocabulary test $(M=35.5$ and 35.5 for young and older adults, respectively). The older adults had a slightly higher level of education $(M=15.0)$ than did the young adults $(M=14.6)$. The groups did not differ reliably on either education level or vocabulary score, however.

Apparatus. The stimuli in this and in subsequent experiments were presented and controlled by an Apple IIe microcomputer equipped with a Mountain Hardware clock that provided accuracy to the nearest millisecond. A Gerbrands G1341T electronic voice key was integrated with the computer to detect voice onsets.

Materials. The word list consisted of stimuli used by Lorch (1982). The critical items were based on 96 sets of triplets. Each triplet included the to-be-satiated word, along with a high-strength and low-strength pairmate. Half of these triplets were categoryexemplar pairs that were selected by Lorch from the Battig and Montague (1969) norms and the Shapiro and Palermo (1970) norms. The remaining half of the triplets were free associates selected by Lorch from the Jenkins (1970) and Keppel and Strand (1970) norms. Lorch also equated the stimuli across levels of strength on the basis of frequency of usage (on the basis of the Kučera and Francis, 1967, norms), length in letters, and type of initial word phoneme across the levels of strength. In order to generate unrelated pairs, each of the two pairmates for a given repeated word were paired with a different target word. Hence, the same stimuli occurred in both related and unrelated conditions for a given level of strength. Stimulus lists were constructed so that all subjects received the same 96 repeated words, the only difference being the number of repetitions and the pairmate word for the relatedness decision. Because there were three repetition conditions, two levels of relatedness, and two levels of strength, there were 12 lists constructed to ensure complete counterbalancing. The subjects did not see any word for more than one trial within an experimental session, and the order of trials was randomized anew for each subject. 
In addition to the 96 critical test trials, there was a total of 28 additional pairs that were selected for practice and buffer trials, which included both high-strength and low-strength related and unrelated conditions. The first 24 trials were practice trials, which were followed by two test blocks. Each test block included 48 test trials, which were preceded by 2 buffer trials.

Procedure. During each trial, the following sequence of events occurred: (1) the to-be-satiated word was presented at the center of the CRT; (2) the subject's pronunciation of the word resulted in the removal of the word from the screen; (3) a 300-msec blank screen was presented; (4) the to-be-satiated word was then repeated the number of times defined by the repetition condition $(2,12,22)$ (5) $300 \mathrm{msec}$ after the last onset of the pronunciation of the repeated word, the repeated word and a related or unrelated pairmate appeared in the center of the CRT; (6) the subject pressed the "/" key, to indicate that the two words were related, or the " $z$ " key, to indicate that the two words were unrelated; (7) a 300-msec blank screen was presented; (8) the subject received a feedback message (i.e., " correct" or "incorrect"); (9) the subject pressed a key to begin a 2,000 -msec intertrial interval. The subjects were encouraged to respond as quickly and as accurately as possible in making their relatedness judgments.

The experiment took place in a sound-attenuated room. The subjects were seated approximately $60 \mathrm{~cm}$ from the computer screen. During the first 24 practice trials, the experimenter remained with the subject to ensure that the subject fully understood the procedures of the experiment. The subjects were given a short break after the practice trials and after the first block of 48 test trials. Also, the subjects were able to take a break at any point during the experiment. No time limits were imposed on the length of these breaks. After the experiment, the subjects were given another short break, and then they were administered Items 16-40 of the WAIS vocabulary test along with a short questionnaire that included questions about health and demographic variables, such as number of years of education. The duration of the experiment ranged from 50 to $75 \mathrm{~m}$.

Design. The design was a 2 (age: young vs. old) $\times 2$ (strength: high vs. low) $\times 2$ (relatedness: related vs. unrelated) $\times 3$ (repetition: $2,12,22$ ) mixed-factor design. Age was the only betweensubjects factor. There were eight observations per subject per cell.

\section{Results}

Each subject's mean response latency and standard deviation was first calculated. Any response that was below $200 \mathrm{msec}$ or 2.5 standard deviations below the subject's mean or above $3,000 \mathrm{msec}$ or 2.5 standard deviations above the subject's mean were treated as outliers. A mean percentage correct based on the number of trials that were neither outliers nor "incorrect" was calculated for each cell. This procedure was used for all four experiments.

Response latencies. Table 2 displays the mean onset latencies and percentages correct for the targets as a function of relatedness, strength of association, and repetition for the young and older adults. There are five major points to note from Table 2: First, as expected, older adults produced slower onset latencies than did young adults. Second, subjects responded faster to related pairs than to unrelated pairs. Third, the relatedness effect was larger for highstrength pairs than for low-strength pairs. Fourth, older adults produced a larger relatedness effect than did young adults. Fifth, and most importantly, the relatedness effect appears to decrease across repetition for the young adults (thereby indicating satiation), but not for the older adults.

These observations were supported by a 2 (age) $\times 2$ (high-strength vs. low-strength) $\times 2$ (related vs. unre-
Table 2

Mean Response Latency (RT, in Milliseconds) and Percentage Correct as a Function of Age, Strength of Association, Relatedness, and Repetition in Experiment 1

\begin{tabular}{|c|c|c|c|c|c|c|}
\hline \multirow[b]{3}{*}{ Relatedness } & \multicolumn{6}{|c|}{ Repetitions } \\
\hline & \multicolumn{2}{|c|}{2} & \multicolumn{2}{|c|}{12} & \multicolumn{2}{|c|}{22.} \\
\hline & RT & $\%$ & $\mathrm{RT}$ & $\%$ & RT & $\%$ \\
\hline \multicolumn{7}{|c|}{ Younger Adults } \\
\hline \multicolumn{7}{|c|}{ High-Strength Associates } \\
\hline Related & 906 & 94 & 920 & 97 & 913 & 97 \\
\hline Unrelated & 1,080 & 86 & 1,044 & 92 & 1,026 & 92 \\
\hline Effect & 174 & 08 & 124 & 05 & 113 & 05 \\
\hline \multicolumn{7}{|c|}{ Low-Strength Associates } \\
\hline Related & 993 & 88 & 1,048 & 84 & 1,011 & 88 \\
\hline Unrelated & 1,082 & 89 & 1,087 & 92 & 1,054 & 94 \\
\hline Effect & 89 & -01 & 39 & -08 & 43 & -06 \\
\hline \multicolumn{7}{|c|}{ Older Adults } \\
\hline \multicolumn{7}{|c|}{ High-Strength Associates } \\
\hline Related & 1,339 & 93 & 1,338 & 94 & 1,344 & 95 \\
\hline Unrelated & 1,597 & 84 & 1,646 & 88 & 1,679 & 89 \\
\hline Effect & 258 & 09 & 308 & 06 & 335 & 06 \\
\hline \multicolumn{7}{|c|}{ Low-Strength Associates } \\
\hline Related & 1,502 & 88 & 1,549 & 88 & 1,491 & 81 \\
\hline Unrelated & 1,656 & 87 & 1,639 & 87 & 1,683 & 86 \\
\hline Effect & 154 & 01 & 90 & 01 & 192 & -05 \\
\hline
\end{tabular}

lated) $\times 3$ (repetition) mixed-factor analysis of variance (ANOVA). This analysis yielded main effects of age $\left[F(1,70)=36.35, M S_{\mathrm{e}}=1,636,664, p<.001\right]$, relatedness $\left[F(1,70)=63.96, M S_{\mathrm{e}}=86,493, p<.001\right]$, and strength $\left[F(1,70)=81.82, M S_{\mathrm{e}}=16,967, p<.001\right]$. This analysis also yielded a strength $\times$ relatedness interaction $\left[F(1,70)=67.40, M S_{e}=11,115, p<.001\right]$, indicating that the relatedness effect was larger for high-strength pairs $(218 \mathrm{msec})$ than for low-strength pairs $(101 \mathrm{msec})$.

There were a number of interactions involving age as a factor. First, this analysis yielded an age $\times$ relatedness interaction $\left[F(1,70)=9.85, M S_{\mathrm{e}}=86,493, p<.005\right]$, indicating that the relatedness effect was larger for older adults ( $222 \mathrm{msec}$ ) than for young adults $(97 \mathrm{msec})$. Second, there was also an age $\times$ relatedness $\times$ strength interaction $\left[F(1,70)=6.88, M S_{\mathrm{e}}=11,115, p<.01\right]$, indicating that strength of association modulated the relatedness effect more for older adults than for young adults. Most importantly, this analysis also yielded a significant age $\times$ relatedness $\times$ repetition interaction $[F(2,140)=3.46$, $\left.M S_{\mathrm{e}}=16,080, p<.05\right]$, indicating that the relatedness effect decreased ( $53 \mathrm{msec}$ ) across repetition conditions for the young adults, and actually increased $(57 \mathrm{msec})$ across repetition conditions for the older adults. Separate ANOVAs on the young and older adult data indicated that there was a reliable relatedness $\times$ repetition interaction for the young adults $\left[F(2,70)=3.13, M S_{\mathrm{e}}=10,379, p<\right.$ $.05]$, whereas for the older adults, there was no hint of relatedness $\times$ repetition interaction $(F<1.00)$. This pattern is consistent with the prediction that older adults might produce less satiation than young adults.

Accuracy. When we turn to the accuracy data displayed in Table 2, there are four points to note: First, young 
adults were slightly more accurate than older adults. Second, subjects were overall more accurate when responding to related pairs than when responding to unrelated pairs. Third, subjects responded more accurately to highly associated pairs than to weakly associated pairs. Fourth, it appears that the relatedness effect decreased across repetition equally for both young and older adults.

The ANOVA yielded main effects of age $[F(1,70)=$ 5.94, $\left.M S_{\mathrm{e}}=288.52, p<.02\right]$ and strength $[F(1,70)=$ $\left.27.45, M S_{e}=47.71, p<.001\right]$. This analysis also yielded a strength $\times$ relatedness interaction $[F(1,70)=39.76$, $\left.M S_{\mathrm{e}}=124.62, p<.001\right]$, indicating that the relatedness effect was larger for high-strength associates $(6.5 \%)$ than for low-strength associates $(3.0 \%)$. There were also a number of interactions involving age as a factor. First, there was an age $\times$ repetition interaction $[F(2,140)$ $\left.=2.93, M S_{\mathrm{e}}=111.58, p<.05\right]$, indicating that young adults became more accurate as repetition increased, but that older adults actually became less accurate as repetition increased. Second, there was an age $\times$ strength $\times$ repetition interaction $\left[F(2,140)=3.20, M S_{\mathrm{e}}=88.17\right.$, $p<.05]$. However, because relatedness did not participate in this interaction, and because strength is only relevant regarding the relatedness dimension, we consider this marginal effect most likely spurious. Finally, it is important to note that although there was some evidence of the relatedness effect decreasing as a function of repetition in the accuracy data, neither the relatedness $\times$ repetition interaction nor the age $\times$ relatedness $X$ repetition interactions approached significance $(F<1.00)$. Thus, the accuracy data did not produce a reliable influence of satiation.

\section{Discussion}

Several aspects of Experiment 1 are noteworthy. First, Experiment 1 provides converging evidence with the work of L. C. Smith (1984; L. C. Smith \& Klein, 1990), which indicates that young subjects do produce semantic satiation when they are required to make relatedness judgments. Second, there was no evidence that there was more satiation for high-strength pairs than for low-strength pairs. In fact, if anything, there was slightly more satiation for the low-strength pairs in the accuracy data (3\% change in the relatedness effect for high-strength items and 5.5\% change for the low-strength items). Moreover, if one considers the percentage change of the relatedness effect across repetitions for the young adults, one finds that for the high-strength pairs there was a $35 \%$ change (i.e., $61 / 174 \mathrm{msec}$ ), whereas for the low-strength pairs there was a $52 \%$ change (i.e., $46 / 89 \mathrm{msec}$ ). Although we will return to this tendency below, clearly the present results do not provide any evidence in support of the initial prediction that there should be more satiation for high-strength pairs than for low-strength pairs. Finally, the results of Experiment 1 provide evidence consistent with the prediction that older adults will produce less satiation than will young adults. Thus, this pattern is quite consistent with the observation that older adults are also less likely to pro- duce verbal transformation effects (see, e.g., Warren \& Warren, 1966; Yin \& MacKay, 1992).

\section{EXPERIMENT 2}

The goal of the second experiment was to further explore the constraints of semantic satiation and also provide a replication of the decreased sensitivity to satiation in older adults as compared with young adults. One of the concerns with Experiment 1 and the previous satiation studies is that there is some degree of predictability when the target pair is presented for the relatedness judgment. In particular, in the first experiment, the target pair was presented after 2,12 , or 22 presentations of the tobe-satiated word, and in the previous studies by L. C. Smith (1984; L. C. Smith \& Klein, 1990), the target pair was presented after either 3 or 33 presentations of the tobe-satiated word. It is possible that subjects begin to realize across trials that the pairs for the relatedness judgments are presented after a given number of trials, and that they engage in strategies (such as counting) that could modulate the obtained satiation effect. Moreover, it is possible that young adults were more likely to engage in such a strategy than older adults. Thus, we believe that it is important to demonstrate satiation effects under conditions in which subjects cannot predict when the target pair is presented. Therefore, the number of presentations of the to-be-satiated word was randomly varied in the second experiment from 1 to 24 . In this way, we sought to minimize any predictive strategies.

A second concern about the design of Experiment 1 was that the subjects pronounced the to-be-satiated word aloud during each trial. Possibly, the observed satiation was related to outputting the stimulus and would not be observed in a context in which there was more passive visual presentation. Therefore, to address this possibility, in Experiment 2, the subjects did not overtly produce the to-be-satiated word aloud during each presentation. If overt speech and/or auditory input from that speech is necessary for satiation to occur, one would expect an elimination of the semantic satiation effect in Experiment 2.

\section{Method}

Subjects. Forty-eight young adults and 48 older adults participated in Experiment 2 . The mean age for the young adults was 21 years, and their ages ranged between 18 and 43 years; the mean age for the older adults was 71 years, and their ages ranged between 59 and 83 years. The young adults ( 15.4 years) had slightly more education than did the older adults ( 14.8 years), but this difference did not reach significance. The older adults scored significantly higher on Items $16-40$ of the vocabulary subsection of the WAIS (44.3) than did the young adults $[41.1 ; t(94)=2.38, p<.02]$.

Materials. The materials used in Experiment 1 were also used in Experiment 2. The list counterbalancing used in Experiment 1 was again used in Experiment 2, with the exception that the eight conditions per subject cell were assigned, without replacement, to repetitions of 1-8 (short repetition condition), 9-16 (medium repetition condition), or 17-24 (long repetition condition). As discussed below, we collapsed across these three levels of repetition to make the present study comparable to the three levels of repetition used in the previous experiment. 
Procedure. The procedure for Experiment 2 was the same as that for Experiment 1 with the following exceptions: (1) the repeated word was presented randomly from 1 to 24 times; (2) the subjects passively watched the repeated word instead of pronouncing the word aloud; (3) the duration of the to-be-satiated word was $600 \mathrm{msec}$, in order to approximate the time taken to name the word aloud in Experiment 1.

\section{Results}

Response latencies. In order to analyze the present results in a manner comparable to that for Experiment 1, we calculated mean response latencies and accuracies for three repetition conditions (short, medium, and long) that referred to the three multiples $(1-8,9-16,17-24)$ of eight satiation trials.

In Table 3, the mean response latencies and percentage correct are presented as a function of relatedness, strength of association, and repetition, for young and older adults. There are four points to note. First, the older adults were again consistently slower than the young adults. Second, subjects responded faster to related pairs than to unrelated pairs. Third, the relatedness effect was larger for high-strength pairs than for low-strength pairs. Fourth, and most importantly, as in Experiment 1, the relatedness effect decreased across repetition for young adults but not for older adults.

These observations were supported by a 2 (age) $\times$ 2 (relatedness) $\times 2$ (strength) $\times 3$ (repetition) mixedfactor ANOVA. This ANOVA yielded main effects of age $\left[F(1,94)=84.77, M S_{\mathrm{e}}=616,771, p<.001\right]$, relatedness $\left[F(1,94)=125.35, M S_{\mathrm{e}}=41,654, p<.001\right]$, repetition $\left[F(2,188)=9.56, M S_{\mathrm{e}}=13,703, p<.001\right]$, and strength $\left[F(1,94)=150.13, M S_{\mathrm{e}}=14,560, p<.001\right]$. This analysis also yielded a reliable relatedness $\times$ strength

Table 3

Mean Response Latency (RT, in Milliseconds) and Percentage Correct as a Function of Age, Strength of Association, Relatedness, and Repetition in Experiment 2

\begin{tabular}{|c|c|c|c|c|c|c|}
\hline \multirow[b]{3}{*}{ Relatedness } & \multicolumn{6}{|c|}{ Mean Number of Repetitions } \\
\hline & \multicolumn{2}{|c|}{4.5} & \multicolumn{2}{|c|}{12.5} & \multicolumn{2}{|c|}{20.5} \\
\hline & RT & $\%$ & RT & $\%$ & RT & $\%$ \\
\hline \multicolumn{7}{|c|}{ Younger Adults } \\
\hline \multicolumn{7}{|c|}{ High-Strength Associates } \\
\hline Related & 796 & 95 & 841 & 98 & 801 & 95 \\
\hline Unrelated & 951 & 89 & 961 & 90 & 919 & 89 \\
\hline Effect & 155 & 06 & 120 & 08 & 118 & 06 \\
\hline \multicolumn{7}{|c|}{ Low-Strength Associates } \\
\hline Related & 875 & 91 & 857 & 88 & 904 & 86 \\
\hline Unrelated & 981 & 87 & 951 & 92 & 956 & 91 \\
\hline Effect & 106 & 04 & 94 & -04 & 52 & -05 \\
\hline \multicolumn{7}{|c|}{ Older Adults } \\
\hline \multicolumn{7}{|c|}{ High-Strength Associates } \\
\hline Related & 1,174 & 95 & 1,150 & 95 & 1,129 & 96 \\
\hline Unrelated & 1,410 & 89 & 1,327 & 92 & 1,368 & 93 \\
\hline Effect & 236 & 06 & 177 & 03 & 239 & 03 \\
\hline \multicolumn{7}{|c|}{ Low-Strength Associates } \\
\hline Related & 1,360 & 86 & 1,293 & 88 & 1,318 & 88 \\
\hline Unrelated & 1,461 & 86 & 1,441 & 91 & 1,387 & 92 \\
\hline Effect & 101 & 0 & 148 & -03 & 69 & -04 \\
\hline
\end{tabular}

interaction $\left[F(1,94)=26.39, M S_{\mathrm{e}}=17,282, p<.001\right]$, indicating that the relatedness effect was larger for highstrength pairs $(174 \mathrm{msec})$ than for low-strength pairs (95 msec).

In addition to these effects, a number of interactions involving age reached significance. First, the age $\times$ relatedness interaction indicated that older adults produced a larger relatedness effect $(162 \mathrm{msec})$ than did young adults $\left[108 \mathrm{msec} ; F(1,94)=5.11, M S_{\mathrm{e}}=41,654\right.$, $p<.05]$. Second, the age $\times$ strength interaction was reliable $\left[F(1,94)=17.38, M S_{\mathrm{e}}=14,560, p<.001\right]$, indicating that there was a larger difference between highstrength and low-strength pairs for the older adults than for the young adults. Third, the age $\times$ strength interaction was qualified by an age $X$. strength $\times$ relatedness interaction $\left[F(1,94)=4.33, M S_{\mathrm{e}}=17,282, p<.05\right]$, which indicated that the influence of strength on the relatedness effect was much larger for the older adults $(172 \mathrm{msec})$ than for the young adults $(62 \mathrm{msec})$. Fourth, the analysis yielded an age $\times$ repetition interaction, indicating that response latencies decreased more as a function of repetition for older adults than for young adults $[F(1,94)=$ 3.63, $\left.M S_{\mathrm{e}}=13,703, p<.05\right]$.

Although the overall analysis did not yield a reliable age $X$ relatedness $\times$ repetition interaction, as shown in Table 3 , it does appear that young and older adults produced a different pattern of results with respect to the relatedness effect across repetitions. As one can see, the relatedness effect decreased by $46 \mathrm{msec}$ across repetition for the young, whereas, for the older adults, the relatedness effect decreased by only $9 \mathrm{msec}$. A separate 2 (strength) $\times 2$ (relatedness) $\times 3$ (repetition) ANOVA was conducted for each group of subjects. In the case of young adults, the ANOVA yielded a significant relatedness $\times$ repetition interaction $\left[F(2,94)=4.95, M S_{\mathrm{e}}=25,526, p<.05\right]$, indicating that the relatedness effect reliably decreased as a function of repetition. The same ANOVA of the older adult data did not approach significance $(F<1.00)$, indicating that there was no evidence of a decrease in the relatedness effect as a function of repetition.

Accuracy. There are four major points to note from the accuracy data displayed in Table 3 . First, subjects responded more accurately to related decision pairs than to unrelated decision pairs. Second, subjects responded more accurately to highly associated word pairs than to weakly associated word pairs. Third, the relatedness effect does not appear to be modulated by strength of association. Fourth, the relatedness effect decreased as a function of repetition for both young adults and older adults.

The ANOVA yielded main effects of strength $[F(1,94)$ $\left.=54.74, M S_{\mathrm{e}}=.61, p<.001\right]$, repetition $[F(1,94)=$ $\left.3.48, M S_{\mathrm{e}}=2.41, p<.05\right]$, and relatedness $[F(1,94)=$ $\left.7.30, M S_{\mathrm{e}}=5.01, p<.05\right]$. The analysis also yielded a strength $\times$ relatedness interaction $\left[F(1,94)=41.93, M S_{\mathrm{e}}\right.$ $=.64, p<.001]$, indicating that the relatedness effect was larger for high-strength pairs $(5.3 \%)$ than for lowstrength pairs $(-2.0 \%)$. More importantly, the analysis also yielded a reliable relatedness $\times$ repetition interaction 
$\left[F(2,188)=4.80, M S_{\mathrm{e}}=.62, p<.01\right]$, indicating that the relatedness effect decreased as a function of repetition for both young and older adults. It should be noted that although the strength $\times$ repetition $\times$ relatedness interaction did not reach significance $[F(2,188)=.86$, $\left.M S_{\mathrm{e}}=.86\right]$, there was a reliable interaction between repetition and relatedness for the low-strength pairs $\left[F(2,188)=3.23, M S_{\mathrm{e}}=1.02, p<.05\right]$, but not for the high-strength pairs $(F<1.0)$.

\section{Discussion}

The major goal of Experiment 2 was to replicate the results obtained in Experiment 1, under conditions in which (1) subjects did not pronounce aloud the prime stimulus and (2) there was relatively little predictability of when the pair for the relatedness decision would be presented. The results of this experiment replicated the pattern of results observed in Experiment 1. Specifically, reliable satiation was observed in response latencies for the young adults, but there was no evidence of satiation for the older adults. In fact, the amount of satiation for the young adults between the short repetition condition and the long repetition condition was remarkably similar across Experiment $1(54 \mathrm{msec})$ and Experiment $2(46 \mathrm{msec})$. Thus, predictability and overt naming do not appear to be necessary conditions for satiation to be observed. In addition, there was again a tendency for more satiation to be produced for the low-strength pairs than for the highstrength pairs. For example, if one considers the accuracy data, there is a $1.5 \%$ change in the relatedness effect across repetition for the high-strength pairs, but a $6.5 \%$ change in the effect for the low-strength pairs. Moreover, this is also again consistent with the observation that if one considers the percentage change of the relatedness effect across repetitions for the young adults in the response latency data, there is a $24 \%$ change for the highstrength pairs $(37 / 155 \mathrm{msec})$ and $51 \%$ change for the low-strength pairs $(54 / 106 \mathrm{msec})$. We will return to this issue in the General Discussion section.

When we turn to the data from the older adults, it is again clear that there was no satiation for these individuals, at least in the response latency data. It should be noted here that this is not simply due to a lack of sensitivity in these subjects. In fact, the main effects of both relatedness and repetition and the strength $\times$ relatedness interactions were reliably larger in the older adults than in the young adults. Thus, if anything, on the basis of this pattern, one would expect larger effects of satiation in older adults than in young adults. However, in both the first and the second experiments, there was no evidence of satiation in the response latency data. It should also be noted here that there was evidence of some satiation in the accuracy data for the older adults in both Experiments 1 and 2. However, the conclusion that older adults are not as sensitive to semantic satiation in the response latency data is not compromised by a larger influence of satiation in the accuracy data in older adults than in young adults, because both groups produced an identical $4 \%$ change in the relatedness effect across the short to the long repetition conditions.

\section{EXPERIMENT 3}

In Experiment 3, we were interested in examining whether satiation would also occur for other processing dimensions. Because words afford multiple processing dimensions (e.g., orthographic, phonological, syntactic, semantic), one might expect satiation to occur for all processing dimensions available for words. Alternatively, one might argue that because words are most naturally processed at the semantic level, and because this level of lexical information may in fact be the most elaborate, one might not find satiation effects for "other" processing dimensions. In order to pursue satiation for other lexical processing codes, in Experiment 3, we used the same presentation format that was utilized in Experiment 2, but instead of now accessing information for relatedness decisions, subjects made rhyme decisions. Specifically, subjects were instructed to decide whether a repeated word such as SAME rhymed with its pairmate CLAIM. In this way, we attempted to provide information about the satiation of underlying phonological codes.

In addition to addressing satiation of phonological codes, Experiment 3 also included a word-frequency manipulation of the to-be-satiated word. This manipulation was included because it was possible that the relative uniqueness of the stimulus might modulate the degree of attentional processing, and hence satiation. Specifically, for relatively high-frequency common words, attentiondemanding lexical processing might be somewhat minimized. On the other hand, for low-frequency words, there might be an increased influence of attention demanding lexical processing, and hence, one might observe relatively more satiation for these stimuli.

The design of Experiment 3 was quite similar to that of the previous experiments, with the exception that subjects made rhyme judgments instead of relatedness judgments, and word-frequency replaced the strength manipulation used in the previous experiments.

\section{Method}

Subjects. Thirty-six young and 36 older adults participated in Experiment 3 . The mean age for the young adults was 21 and their ages ranged from 18 to 26 ; the mean for the older adults was 67 and their ages ranged from 59 to 79 . The mean education level was 14.8 years for the young adults and was 14.5 years for the older adults. The mean scores on the vocabulary subsection of the WAIS (Items 16-40) was 39.55 for the young adults and 42.22 for the older adults. The groups did not reliably differ on education level or on vocabulary scores.

Materials. The word list was based on 48 high-frequency targets and 48 low-frequency targets. The high-frequency words had counts greater than 100 per million and the low-frequency words had counts of less than 5 per million, based on the Kučera and Francis (1967) norms. Each target was paired with a rhyming pairmate and a nonrhyming pairmate for the rhyme decisions. Care was taken 
to ensure that the rhyme decisions could not simply be made on orthographic overlap. Specifically, for a given target word (e.g., CLAIM), the rhyming and nonrhyming pairmates had similar overlaps in letters (e.g., SAME vs. DIME). Counterbalancing insured that each highor low-frequency target word occurred equally across the three levels of repetition and the two levels of rhyming, and that no stimulus was repeated per subject. As in Experiment 2, the three levels of repetition refer to repetitions of 1-8, 9-16, and 17-24.

In addition to the stimuli for the test trials, there were also 16 pairs of items that were selected for practice buffer stimuli. Half of these pairs rhymed and half did not. Subjects received a total of 12 practice satiation trials before receiving two blocks of 50 trials. The first two trials within each test block were buffer trials. All test trials were randomized anew per subject, with the exception that each condition be equally represented across test blocks.

Procedure. The procedure of this experiment was very similar to that for Experiment 2, with the exception that on each trial either a to-be-satiated high- or a to-be-satiated low-frequency word was presented, which was followed by a pair of stimuli. The pair included the to-be-satiated word and its rhyming or nonrhyming pairmate. The subjects were instructed to make rhyme decisions as fast and as accurately as possible.

\section{Results}

Response latencies. Table 4 presents the older and young adult data for Experiment 3 . There are four points to note. First, young adults again responded faster than older adults. Second, subjects responded faster to rhyming pairs than to nonrhyming pairs. Third, the size of the rhyming effect decreased only slightly across repetitions. Fourth, word frequency does not appear to modulate the rhyming effect.

These observations were supported by a 2 (age) $\times 2$ (frequency) $\times 2$ (phonological relatedness) $\times 3$ (repetition) mixed-factor ANOVA. This ANOVA yielded main effects of age $\left[F(1,70)=55.87, M S_{\mathrm{e}}=668,358, p<.001\right]$, frequency $\left[F(1,70)=7.92, M S_{\mathrm{e}}=11,101, p<.01\right]$, and

Table 4

Mean Response Latency (RT, in Milliseconds) and

Percentage Correct as a Function of Age, Frequency, Phonological Relatedness, and Repetition in Experiment 3

\begin{tabular}{|c|c|c|c|c|c|c|}
\hline \multirow[b]{3}{*}{ Phonological Relatedness } & \multicolumn{6}{|c|}{ Mean Number of Repetitions } \\
\hline & \multicolumn{2}{|c|}{4.5} & \multicolumn{2}{|c|}{12.5} & \multicolumn{2}{|c|}{20.5} \\
\hline & RT & $\%$ & RT & $\%$ & RT & $\%$ \\
\hline \multicolumn{7}{|c|}{ Younger Adults } \\
\hline \multicolumn{7}{|l|}{ High Frequency } \\
\hline Rhyming & 839 & 93 & 836 & 95 & 833 & 93 \\
\hline Nonrhyming & 948 & 87 & 940 & 92 & 915 & 91 \\
\hline Effect & 109 & 06 & 104 & 03 & 82 & 02 \\
\hline \multicolumn{7}{|l|}{ Low Frequency } \\
\hline Rhyming & 822 & 92 & 846 & 93 & 827 & 95 \\
\hline Nonrhyming & 926 & 90 & 913 & 92 & 913 & 92 \\
\hline Effect & 104 & 02 & 67 & 01 & 86 & 03 \\
\hline \multicolumn{7}{|c|}{ Older Adults } \\
\hline \multicolumn{7}{|l|}{ High Frequency } \\
\hline Rhyming & 1,217 & 92 & 1,223 & 94 & 1,270 & 92 \\
\hline Nonrhyming & 1,368 & 92 & 1,394 & 94 & 1,391 & 92 \\
\hline Effect & 151 & 0 & 171 & 0 & 121 & 0 \\
\hline \multicolumn{7}{|l|}{ Low Frequency } \\
\hline Rhyming & 1,204 & 93 & 1,267 & 92 & 1,271 & 90 \\
\hline Nonrhyming & 1,307 & 93 & 1,314 & 93 & 1,322 & 94 \\
\hline Effect & 103 & 0 & 47 & -01 & 51 & -04 \\
\hline
\end{tabular}

phonological relatedness $\left[F(1,70)=50.42, M S_{\mathrm{e}}=42,656\right.$, $p<.001]$. The ANOVA also yielded a reliable frequency $\times$ phonological relatedness interaction $[F(1,70)=6.56$, $\left.M S_{\mathrm{e}}=18,018, p<.05\right]$, which indicated that the effect of phonological relatedness was greater for high-frequency words (123 msec) than for low-frequency words $(76 \mathrm{msec})$. Because the high- and low-frequency words were paired with different target stimuli, it is possible that this interaction may be due to simple differences in difficulty of the selected pairs. More importantly, as shown in Table 4, there is very little evidence of satiation for either the young or the older adults. In fact, neither the phonological relatedness $\times$ repetition interaction $[F(2,140)=1.33$, $\left.M S_{\mathrm{e}}=13,701, p=.27\right]$ nor the frequency $\times$ phonological relatedness $\times$ repetition interaction $[F(2,140)<1.00]$ approached significance. It is of course possible that the variability in the older adults reduced our power to detect a reliable phonological relatedness $\times$ repetition interaction, but separate analyses of each age group indicated that all interactions with repetition and relatedness as factors produced $F \mathrm{~s}<1.00$.

Accuracy. As can be seen in Table 4, there appears to be some tendency for the phonological relatedness effect to decrease slightly across repetitions in the accuracy data; however, the relatedness $\times$ repetition interaction did not approach significance $[F(2,140)<1.00]$. In fact, the only reliable effect produced from the ANOVA on the accuracy data was a reliable age $\times$ relatedness interaction $\left[F(1,70)=5.62, M S_{\mathrm{e}}=.844, p<.05\right]$, which indicated that young adults were slightly more accurate $(2.7 \%)$ for rhyming pairs than for nonrhyming pairs, whereas older adults were slightly less accurate (1\%) for rhyming pairs than for nonrhyming pairs.

\section{Discussion}

One of the major motivations for conducting Experiment 3 was to determine whether other codes that are available in lexical processing also produce a satiation-type effect. In particular, we were interested in the availability of phonological information for rhyme decisions. The results of Experiment 3 provided little evidence for phonological satiation for either high-frequency or low-frequency words. Although there was a tendency for the phonological relatedness effect to decrease across repetitions, this tendency did not approach statistical significance. Clearly, one must treat the failure to reject the null hypothesis with some caution; however, the lack of an effect in both response latencies and accuracy suggests that the phonological code is not as susceptible to satiation as is the semantic code. Possibly, if subjects overtly named the tobe-satiated word, and hence increased the analysis of phonological information, one might be more likely to find evidence of a type of phonological satiation. In fact, Esposito and Pelton (1971) have suggested that the apparent attenuation in meaning following a satiation manipulation in past studies may have been due to a type of phonological satiation produced by the naming of the tobe-satiated word. Although overt naming may increase the likelihood of obtaining a type of phonological satia- 
tion effect, the present Experiments 2 and 3 indicate that under identical passive presentation conditions, there is evidence of semantic satiation (in Experiment 2) and relatively little evidence of phonological satiation (in Experiment 3 ). Thus, we feel comfortable in suggesting that semantic codes appear to be more susceptible to satiation under a passive viewing condition than are phonological codes.

\section{EXPERIMENT 4}

Although the results of Experiments 1 and 2 provided support for semantic satiation, a simple alternative explanation still needed to be addressed. That is, it is possible that the mere repetition of a word modulates attentional alertness and hence decreases the semantic relatedness effect at the longer repetitions. This would suggest that semantic satiation type effects might be due to a simple change in attentional alertness possibly because of a type of boredom that might result from the repetitive nature of the satiating stimulus. Of course, such an account would not involve semantic satiation of the underlying representation but rather would suggest that any manipulation that decreases attentional alertness might also decrease the effects of semantic relatedness.

Experiment 4 was conducted to determine the influence of mere repetition of a stimulus word on later semantic relatedness judgments. This experiment involved precisely the same procedures and materials that were used in Experiment 2, with the exception that stimuli were rotated so that the repeated word was always unrelated to the pair of words that was presented in the relatedness decision. In this way, the results of Experiment 4 would provide a baseline for estimating the influence of simple repetition of a stimulus word on later relatedness judgments. If attentional capacity is diminished by repetition of a stimulus, one should again find that the relatedness effect decreases as a function of repetition, at least for the young adult subjects. On the other hand, no change in the semantic relatedness effect, or an increase in the relatedness effect across repetitions, would ensure that the satiation effect found in the first two experiments does not reflect a type of attentional change due to repetition.

\section{Method}

Subjects. Thirty-six young adults and 36 older adults participated in Experiment 4. The mean age for the young adults was 19 years, and their ages ranged from 18 to 22; the mean age for the older adults was 72 years, and their ages ranged from 59 to 83 . The young adults (13.9 years) had slightly more education than did the older adults (13.7 years). The older and young adults scored the same on Items $16-40$ of the vocabulary subsection of the WAIS (42). Again. the groups did not reliably differ on education or vocabulary scores

Materials. The materials used in Experiment 2 were also used in Experiment 4 . The only difference between Experiments 2 and 3 was in the configuration of the stimuli. In this experiment, the tobe-satiated word was always unrelated to the pair of words that were presented for the relatedness decision. For example, on a related trial subjects might repeatedly receive the word CAR followed by either the related pair APPLE-ORANGE or the unrelated pair APPLE-CHAIR.
Procedure. The procedure for Experiment 4 was precisely the same as that for Experiment 2.

\section{Results}

Response latencies. Table 5 presents the mean response latencies and percentages correct as a function of relatedness, strength of association, and repetition for the young and older adults. There are four major points to note from Table 5. First, older adults were again slower than young adults. Second, response latencies were faster to related pairs than to unrelated pairs. Third, the effect of relatedness was much larger for high-strength pairs than for low-strength pairs. Fourth, and most importantly, the relatedness effect does not decrease as a function of repetition for either the young adults or the older adults. In fact, there is a slight increase in the relatedness effect as a function of repetition.

These observations were supported by a 2 (age) $\times 2$ (strength) $\times 2$ (relatedness) $\times 3$ (repetition) mixed-factor ANOVA. This analysis yielded main effects of age $[F(1,70)$ $\left.=19.26, M S_{\mathrm{e}}=1,628,123, p<.001\right]$, strength $[F(1,70)=$ $\left.44.17, M S_{\mathrm{e}}=15,369, p<.001\right]$, relatedness $[F(1,70)=$ $\left.75.00, M S_{\mathrm{e}}=79,092\right]$, and repetition $[F(2,140)=15.26$, $\left.M S_{\mathrm{e}}=19,498, p<.001\right]$. There were also three reliable two-way interactions. First, there was an age $\times$ strength interaction $\left[F(1,70)=8.34, M S_{\mathrm{e}}=15,369, p<.01\right]$, which indicated that the difference between high-strength and low-strength pairs was larger for older adults $(75 \mathrm{msec})$ than for young adults $(32 \mathrm{msec})$. Second, there was an age $\times$ relatedness interaction $\left[F(1,70)=7.37, M S_{\mathrm{e}}=\right.$ $79,092, p<.01]$, which indicated that the relatedness effect was larger for older adults $(218 \mathrm{msec})$ than for the young adults $(115 \mathrm{msec})$. Third, there was a reliable

Table 5

Mean Response Latency (RT, in Milliseconds) and Percentage Correct as a Function of Age, Strength of Association, Relatedness, and Repetition in Experiment 4

\begin{tabular}{|c|c|c|c|c|c|c|}
\hline \multirow[b]{3}{*}{ Relatedness } & \multicolumn{6}{|c|}{ Mean Number of Repetitions } \\
\hline & \multicolumn{2}{|c|}{4.5} & \multicolumn{2}{|c|}{12.5} & \multicolumn{2}{|c|}{20.5} \\
\hline & RT & $\%$ & RT & $\%$ & RT & $\%$ \\
\hline & \multicolumn{6}{|c|}{ Younger Adults } \\
\hline \multicolumn{7}{|c|}{ High-Strength Associates } \\
\hline Related & 1,220 & 92 & 1,111 & 94 & 1,099 & 95 \\
\hline Unrelated & 1,364 & 88 & 1,283 & 92 & 1,297 & 93 \\
\hline Effect & 144 & 04 & 172 & 02 & 198 & 02 \\
\hline \multicolumn{7}{|c|}{ Low-Strength Associates } \\
\hline Related & 1,248 & 82 & 1,217 & 85 & 1,233 & 85 \\
\hline Unrelated & 1,317 & 91 & 1,272 & 93 & 1,277 & 95 \\
\hline Effect & 69 & -09 & 55 & -08 & 44 & -10 \\
\hline \multicolumn{7}{|c|}{ Older Adults } \\
\hline \multicolumn{7}{|c|}{ High-Strength Associates } \\
\hline Related & 1,462 & 94 & 1,422 & 95 & 1,432 & 95 \\
\hline Unrelated & 1,735 & 85 & 1,722 & 87 & 1,739 & 83 \\
\hline Effect & 273 & 09 & 300 & 08 & 307 & 12 \\
\hline \multicolumn{7}{|c|}{ Low-Strength Associates } \\
\hline Related & 1,652 & 89 & 1,527 & 82 & 1,605 & 85 \\
\hline Unrelated & 1,756 & 88 & 1,690 & 88 & 1,765 & 88 \\
\hline Effect & 104 & 01 & 163 & -06 & 160 & -03 \\
\hline
\end{tabular}


strength $\times$ relatedness interaction $\left[F(1,70)=52.67, M S_{\text {e }}\right.$ $=18,153, p<.001]$, which indicated that the effect of relatedness was larger for high-strength pairs $(233 \mathrm{msec})$ than for low-strength pairs $(100 \mathrm{msec})$. In addition to the two-way interactions, there was also a reliable age $\times$ repetition $\times$ strength interaction $\left[F(2,140)=3.56, M S_{\mathrm{e}}=\right.$ $20,058, p=.05]$. Because relatedness did not participate in the latter interaction, we consider this interaction likely to be spurious. Finally, there was no evidence of a repetition $\times$ relatedness interaction or any higher order interaction in which these two factors participated (all $F_{\mathrm{S}}<1.35$ ).

Accuracy. When we turn to the accuracy data presented in Table 5, there was a main effect of strength $\left[F(1,70)=17.51, M S_{\mathrm{e}}=.774, p<.001\right]$, which indicated that high-strength pairs produced higher accuracy $(91 \%)$ than did low-strength pairs $(87 \%)$. In addition, there were three two-way interactions. First, there was an age $\times$ relatedness interaction $\left[F(1,70)=9.09, M S_{\mathrm{e}}=1.69, p<\right.$ $.005]$, which indicated that the benefit of relatedness was larger for the older adults $(4 \%)$ than for the young adults $(-3 \%)$. Second, there was a strength $\times$ relatedness interaction $\left[F(1,70)=51.99, M S_{\mathrm{e}}=.83, p<.001\right]$, which indicated that there was a facilitatory influence of relatedness for high-strength pairs $(6 \%)$, whereas for lowstrength pairs, there was an inhibitory effect of relatedness $(-6 \%)$. Finally, there was a reliable age $\times$ repetition interaction $\left[F(2,140)=4.03, M S_{\mathrm{e}}=.78, p<.05\right]$, which indicated that overall accuracy increased across repetitions for the young adults $(4 \%)$, whereas for the older adults there was a slight decrease in accuracy $(-1 \%)$. No remaining interactions approached significance (all $F \mathrm{~s}<1.41$ ).

\section{Discussion}

The goal of Experiment 4 was to determine whether the evidence for semantic satiation that was observed in Experiments 1 and 2 could be explained by the simple notion that a generalized fatigue or change in attentional alertness was occurring across the repetitions and whether this factor was the mechanism producing the decreased relatedness effect. This was tested by using the same procedure and materials used in the previous experiments, yet now rotating the repeated word so that it was consistently unrelated to the target. The results of this experiment clearly did not support the generalized fatigue and/or change in attentional alertness/capacity account. In fact, if anything, there was a slight tendency, albeit an unreliable one, for the relatedness effect to actually increase across repetitions in this experiment. This pattern occurred for both young and older adults. Hence, the decrease in the relatedness effect across repetitions that was observed in both Experiments 1 and 2 cannot be attributed to a generalized fatigue and/or change in attentional alertness.

\section{GENERAL DISCUSSION}

The results of the present experiments were straightforward: First, the results of both Experiments 1 and 2 provided evidence for semantic satiation in both the response latencies and accuracies of young adults. Specif- ically, the influence of semantic relatedness decreased as a function of repetition of one of the words involved in the semantic relatedness decision. As noted earlier, this finding is important because there has been considerable controversy regarding semantic satiation effects. In addition to further establishing the reliability of this phenomenon, the present Experiments 1 and 2 provided evidence that semantic satiation is not dependent on (1) overt output of the to-be-satiated word or (2) the predictability of when the stimulus pair for the relatedness decision would be presented. There was also some tendency for greater satiation for low-strength pairs than for highstrength pairs. Finally, the results from both experiments indicated that at least in response latencies, older adults appear to be less sensitive to semantic satiation effects than young adults.

The third and fourth experiments were designed to explore the constraints of the semantic satiation effect. In the third experiment, we explored whether satiation-type effects occur for another type of code that is available for words - that is, phonological codes. In this experiment, instead of making semantic relatedness judgments, the subjects made rhyme judgments. The results provided little evidence of satiation of phonological codes. In Experiment 4 , we explored the possibility that, due to the repetitive presentation of the to-be-satiated word, there might have been a decrease in attentional alertness (fatigue) and this might have reduced the effect of semantic relatedness across repetitions, thereby producing the satiation effects observed in Experiments 1 and 2. However, the results of Experiment 4 indicated that if a word is repeated that is unrelated to the pair of words that are presented for the relatedness decision, there is no evidence for semantic satiation. Hence, a generalized fatigue or decreased attentional alertness is not responsible for the satiation effects observed in the first two experiments.

The remainder of the General Discussion section will focus on the following four issues: (1) alternative accounts of the present satiation-type effects; (2) the role of semantic strength in modulating semantic satiation; (3) the degree to which alternative lexical processing codes are susceptible to semantic satiation; (4) the implications of age-related changes in susceptibility to semantic satiation.

\section{Alternative Accounts of the Present Satiation-Type Effects}

One aspect of the present satiation results is somewhat troublesome. Specifically, if one separately considers the related and unrelated conditions in both Experiments 1 and 2, it appears both that the related condition increases across the number of repetitions and that the unrelated condition decreases across the number of repetitions. Of course, if one could isolate only satiation effects from other factors, one would clearly expect the related condition to increase across repetitions (due to satiation of that node) and the unrelated condition to actually remain relatively stable across repetitions. However, this is not the pattern that was observed. Thus, it is possible that the present satiation-type effect might reflect some other 
processes that are somehow modulating the unrelated condition.

We have three responses to this concern: First, a number of factors are changing across repetition in the present experiments. For example, not only is there the increase in satiation across repetitions, but there is also the influence of repetitions. This repetition-type effect would work against the influence of satiation in the related condition. Thus, one must use an unrelated baseline to control for other extraneous factors such as repetition. In fact, the decrease in response latency in the unrelated condition may be due to a simple repetition effect for the lexical item that ultimately appears in the relatedness judgment for the unrelated conditions. The reason that there is no decrease across repetitions in the related condition, and, in fact, there is a slight increase, is that the repetition effect is being compensated by a satiation effect. Second, if some unknown extraneous factor is producing the present satiation effects, it is unclear why the results of Experiment 4 yielded no evidence of satiation. Clearly, everything was identical in Experiment 4, compared with Experiment 2, with the exception of the fact that the repeated word was not a member of the relatedness judgment. Again, there was no evidence of satiation in Experiment 4 . Third, the results from the older adults are consistent with available evidence concerning satiationtype effects in this population. Specifically, because older adults have already been shown to produce a diminished satiation-type effect in the verbal transformation paradigm, the present results converge on the notion that a similar satiation-type mechanism is being tapped in the present experiments. Thus, because of these three converging pieces of evidence, we believe that the most likely account of the decreased relatedness effect across repetition in the first and second experiments is that this decrease reflects a true satiation effect.

\section{Semantic Strength}

The results of Experiments 1, 2, and 4 provided evidence of a highly reliable strength $\times$ relatedness interaction; that is, the effect of relatedness was much larger for high-strength pairs than for low-strength pairs. However, there was no evidence of greater satiation for the high-strength pairs than for the low-strength pairs. This is somewhat surprising, because one might expect that the semantic features that are most likely to become satiated are those that are most readily available and are shared by the high-strength pairmate. In fact, if anything, the results of Experiments 1 and 2 provide evidence for the opposite conclusion. Specifically, although the results of Experiments 1 and 2 indicated that the relatedness effect decreased across repetition by the same absolute amount for high-strength ( $49 \mathrm{msec})$ and low-strength $(50 \mathrm{msec})$ pairs, if one considers the data as a percentage of the overall relatedness effect, one finds that there is greater change for the low-strength pairs $(70 \%)$ than for the high-strength pairs $(37 \%)$. Interestingly, a similar pattern occurred in the accuracy data. Specifically, for the young adults, the relatedness effect changed by only $1.5 \%$ between the short and long repetition conditions $(F<1.0$ for the relatedness $\times$ repetition interaction), whereas for the low-strength pairs, the relatedness decreased by a reliable $7 \%(p<.05)$. Thus, as noted earlier, there was a tendency for more satiation to be observed for the lowstrength pairs.

Why might high-strength pairs be less susceptible to semantic satiation than low-strength pairs? This pattern could be viewed as consistent with the notion that for high-strength pairs subjects may be able to rely on a relatively shallow nonanalytic comparison of the two words to reach a relatedness decision. High-strength pairs were very clearly related. On the other hand, for the low-strength pairs, subjects may need to engage in a more analytic analysis of the semantic features of the two words. Because this second process demands more detailed semantic analysis, it may be more susceptible to satiation. For example, the decision that BLOSSOM and FLOWERS are related does not demand as much semantic analysis as the decision that BLOSSOM and SPRING are related. Of course, the notion that high- and low-strength pairs engage different levels of semantic analysis is not novel and is quite consistent with the two-stage model of sentence verification developed by E. E. Smith, Shoben, and Ripps (1974). Therefore, the present evidence that there is a tendency for more satiation to occur for lowstrength pairs could be viewed as supporting the notion that decisions that demand relatively in-depth semantic analyses are more susceptible to satiation-type effects. In fact, the notion that the degree of semantic processing is critical in obtaining semantic satiation effects is quite consistent with the initial observation by L. C. Smith (1984) that one does not find semantic satiation effects in the lexical decision task (a task that primarily directs attention to lexical level processes), whereas one clearly finds satiation-type effects in the relatedness judgment task (a task that primarily directs attention to semantic level information).

\section{Phonological Satiation}

The goal of Experiment 3 was to investigate whether other codes available for words are also susceptible to satiation. In pursuit of this goal, we replicated the design of Experiment 2, but now required subjects to make rhyme decisions. In this way, we could test whether the phonological codes that are involved in making rhyme decisions are also susceptible to satiation effects. The results of this experiment provided little evidence for phonological satiation for either high- or low-frequency words. These results are intriguing in light of a number of observations in the extant lexical processing literature. For example, these results are at least somewhat inconsistent with the recent arguments that phonological analyses are a mandatory stage in lexical processing (see Van Orden, 1987). If this were the case, one might expect the repetition of the phonological analysis to satiate these codes. However, one must clearly be cautious here, because this argument is based on a single experiment with a null effect of phonological satiation. 
As noted earlier, we might have been more likely to obtain a phonological satiation effect in Experiment 3 if subjects had been required to pronounce the to-be-satiated word aloud. Although this is possible, results by MacKay et al. (1993) suggest that this might not occur. MacKay et al. found that overt production might in fact diminish satiation, at least as it is measured by the verbal transformation effect. Of course, it is quite likely that the type of phonological analysis engaged in converting orthographic patterns to phonological patterns in visual word recognition is quite different from the processing streams involved in speech processing, as reflected by the verbal transformation effect. (In fact, the sheer number of repetitions in the present experiments is considerably smaller than that for the typical verbal transformation experiment.) Hence, one must again be cautious in making parallels between the present attempt to obtain phonological satiation via rhyme decisions and the evidence from the speech processing literature concerning the verbal transformation effect.

Of course, the more important question is why one would expect more satiation for semantic codes than for phonological codes for visually presented stimuli. We view this pattern as consistent with the inherent bias in the language processing system toward engaging semantic codes. This of course would follow from the primary role that words play in reading: words convey meaning. Hence, attention is most likely driven to such codes during the repetition of the to-be-satiated word. Presumably, the direction of attention to semantic codes eventually makes these codes less available because of a type of satiation. It is possible that manipulations of the direction of attention to alternative processing routes may be more likely to produce satiation-type effects. For example, it may be possible to produce a type of phonological satiation effect when nonwords are presented. Here, the system should be primarily driven by spelling-to-sound correspondences. At the very least, future work is needed in order to explore the sensitivity of alternative processing codes in visual lexical processing to satiation-type effects.

\section{Age-Related Changes in Sensitivity to Semantic Satiation}

One of the most intriguing aspects of the present study is that the results of both Experiments 1 and 2 indicated that older adults were less susceptible, at least as reflected in response latencies, to semantic satiation than young adults. Of course, it is possible that older adults did not produce satiation-type effects in the response latency data because older adults simply produced smaller effects of all variables. However, just the opposite was observed. Specifically, both the effects of relatedness and the strength $X$ relatedness interaction were reliably larger for the older adults than for the young adults. This is quite consistent with the general slowing prediction that absolute effect sizes should increase in older adults as compared with young adults (see, e.g., Myerson, Hale, Wagstaff, Poon, \& Smith, 1990). What is quite intriguing in the present results is that older adults produced a reduced influence of satiation in response latencies when compared with young adults. In fact, if one considers the proportional change in the relatedness effect, the results are quite dramatic. For example, in Experiment 1, the relatedness effect decreased by $41 \%$ for young adults across repetition but actually increased by $22 \%$ for older adults across repetition. In Experiment 2, the relatedness effect decreased by $35 \%$ across repetitions for the young adults and decreased by only $8 \%$ for older adults. Thus, because one would a priori expect larger absolute effects in older adults than in young adults (as observed for both the relatedness and relatedness $\times$ strength interaction), the decreased influence of satiation in the response latency data in the older adults' data cannot be simply accommodated by a general slowing account of age-related changes.

As noted earlier, the observation of age-related changes in satiation is quite consistent with other studies in the extant literature. For example, in the McDowd and Filion (1992) study, young and older adults were told to either listen to a tone and ignore a story or ignore a story and listen to a tone. McDowd and Filion recorded the skin conductance orienting response (SCOR) to a tone stimulus across 20 trials. Two of their findings are particularly relevant to the present results: First, older adults produced less habituation to the tones across trials than did young adults, as evidenced by less of a change in the SCOR to the tones across trials. This is quite consistent with the present results indicating that older adults are less likely to satiate than young adults. Second, McDowd and Filion found that for the young adults the SCOR decreased most dramatically for the ignore-tone condition, compared with the attend-tone condition, whereas, for the older adults, there was no difference between these two conditions. Hence, even when instructions strongly encouraged decreased attention to the tone, there was no evidence of habituation in the older adults.

In addition to the McDowd and Filion (1992) results, as noted earlier, Warren and Warren (1966) and Yin and MacKay (1992) have reported evidence that older adults produce less of a verbal transformation effect than do young adults. Because the verbal transformation effect has been interpreted as evidence of satiation of lexical representations, the present semantic satiation effects are quite consistent with an age-related change in satiation. MacKay et al. (1993) have interpreted these results within MacKay's (1982) node structure theory and the agerelated transmission deficit hypothesis developed by Burke, MacKay, Worthley, and Wade (1991). The basic notion is that there is an age-related decrease in the degree of priming from lexical nodes to appropriate phonological information. Because of this change in the amount of priming, phonologically related lexical representations (SPACE, FACE, PASTE) will not receive as much activation as will the repeated word (e.g., PACE). Because of this decreased priming in older adults, one would expect to find a decrease in the probability of verbal transformations across time, as Warren and Warren (1966) initially reported.

Of course, the present results could also be interpreted within the transmission deficit hypothesis. Specifically, 
one might argue that the activation of lexical and semantic representations from the orthographic pattern is decreased in older adults as compared with young adults. In fact, Balota and Duchek (1988) used a delayed naming paradigm to track early lexical access processes and provided evidence of decreased lexical access processes in older adults as compared with young adults. If there is slowed lexical access from the orthographic code, one would also expect a concomitant decrease in the activation reaching semantic representations. Because satiation is dependent on the extent to which a representation has been activated in the past, one would expect such a decreased lexical access process to ultimately produce a decrease in semantic satiation in older adults.

Finally, we believe that an age-related decrease in satiation/habituation has important ramifications for the information processing system. For example, as Cowan (1988) points out, an important role of habituation is that it allows the organism to filter out repetitive extraneous information, thereby decreasing the allocation of resources to redundant information. The evolutionary significance of such a mechanism is that the processing system will be tuned to information-bearing stimuli, instead of repetitive non-information-bearing stimuli. Given the capacity limitations of the attentional system, the ability to minimize attentional allocation to redundant information is precisely what one would desire in an efficient processing system.

\section{REFERENCES}

Balota, D. A., Black, S. R., \& Cheney, M. (1992). Automatic and attentional processes in young and old adults: Reevaluation of the two-process model of semantic priming. Journal of Experimental Psychology: Human Perception \& Performance, 2, 485-502.

Balota, D. A., \& Chumbley, J. I. (1984). Are lexical decisions good measures of lexical access? The role of word frequency in the neglected decision stage. Journal of Experimental Psychology: Human Perception \& Performance, 10, 340-357.

Balota, D. A., \& DucheK, J. M. (1988). Age related differences in lexical access, spreading activation, and simple pronunciation. Psychology \& Aging, 3, 84-93.

BASSETT, N. F., \& WARNE, C. J. (1919). On the lapse of verbal meaning with repetition. American Journal of Psychology, 30, 415-418.

Battig, W. F., \& Montague, W. E. (1969). Category norms for verbal items in 56 categories: A replication and extension of the Connecticut category norms. Journal of Experimental Psychology Monographs, 80 (3, Pt. 2).

BURKE, D. M., MaCKaY, D. G., WorThley, J. S., \& WADE, E. (1991). On the tip of the tongue: Why do word finding failures increase with age? Journal of Memory \& Language, 36, 542-579.

Cohene, L. S., Smith, M. C., \& Klein, D. (1978). Semantic satiation revisited with a lexical decision task. Memory \& Cognition, 6, 131-140.

Collins, A. M. , \& LofTus, E. F. (1975). A spreading activation theory of semantic processing. Psychological Review, 82, 407-428.

CoWAN, N. (1988). Evolving conceptions of memory storage, selective attention, and their mutual constraints within the human informationprocessing system. Psychological Bulletin, 104, 163-191.

Esposito, N. J., \& Pelton, L. H. (1971). Review of the measurement of semantic satiation. Psychological Bulletin, 75, 330-346.

FORSTER, K. I. (1976). Accessing the mental lexicon. In R. J. Wales \&
E. Walker (Eds.), New approaches to language mechanisms (pp. 257287). Amsterdam: North-Holland.

HARRISON, J. M., \& ISAAC, W. (1985). Disruption and habituation of stable fixed-interval behavior in young and older monkeys. Physiology \& Behavior, 32, 341-344.

Hartley, A. A. (1992). Attention. In F. I. M. Craik \& T. A. Salthouse (Eds.), The handbook of cognitive aging (pp. 3-49). Hillsdale, NJ: Erlbaum.

JENKINS, J. J. (1970). The 1952 Minnesota word association norms. In L. Postman \& G. Keppel (Eds.), Norms of word association (pp. 1-38). New York: Academic Press.

KePPEL, G., \& STRAND, B. Z. (1970). Free association responses to primary responses and other responses selected from the Palermo-Jenkins norms. In L. Postman \& G. Keppel (Eds.), Norms of word association (pp. 177-239). New York: Academic Press.

KUČERA, H., \& FrANCIS, W. N. (1967). Computational analysis of present day American English. Providence, RI: Brown University Press.

LORCH, R. F., JR. (1982). Priming and search processes in semantic memory: A test of three models of spreading activation. Journal of Verbal Learning \& Verbal Behavior, 21, 468-492.

MACKAY, D. G. (1969). Verbal transformation illusion: Satiation or synthesis? Journal of the Acoustical Society of America, 45, 316.

MACKAY, D. G. (1982). The problems of flexibility, fuency, and speed accuracy trade-off in skilled behavior. Psychological Review, 89, 483-506.

MacKAY, D. G. (1990). Perception, action, and awareness: A threebody problem. In O. Neumann \& W. Prinz (Eds.), Relations between perception and action (pp. 269-303). Berlin: Springer-Verlag.

MacKaY, D. G., Wul F, G., YIN, C., \& ABRAMS, L. (1993). Relations between word perception and production: New theory and data on the verbal transformation effect. Journal of Memory \& Language, 32, 624-646.

MCDowD, J. M., \& FILION, D. L. (1992). Aging, selective attention, and inhibitory processes: A psychophysiological approach. Psychology \& Aging, 7, 65-71.

Myerson, J., Hale, S., Wagstaff, D., Poon, L. W., \& Smith, G. A (1990). The information loss model: A mathematical theory of agerelated cognitive slowing. Psycholugical Review, 97, 475-487.

NeELy, J. H. (1977). The effects of visual and verbal satiation on the lexical decision task. American Journal of Psychology, 90, 447-459.

NeELY, J. H. (1991). Semantic priming effects in visual word recognition: A selective review of current findings and theories. In D. Besner \& G. W. Humphreys (Eds.), Basic processes in reading. Hillsdale, NJ: Erlbaum

Shapiro, S. I., \& PALERMo, D. S. (1970). Conceptual organization and class membership: Normative data for representatives of 100 categories. Psychonomic Monograph Supplements, 3 (11, Whole No. 43).

Sмith, E. E., Shoben, E. J., \& RipPS, L. J. (1974). Structure and process in semantic memory: A featural model for semantic decisions. Psychological Review, 81, 214-241.

SMrTH, L. C. (1984). Semantic satiation affects category membership decision time but not lexical priming. Memory \& Cognition, 12, 483-488.

SMiTH, L. C., \& KLEIN, R. (1990). Evidence for semantic satiation: Repeating a category slows subsequent semantic processing. Journal of Experimental Psychology: Learning, Memory, \& Cognition, 16 852-861.

VAN ORDEN, G. C. (1987). A ROWS is a ROSE: Spelling, sound, and reading. Memory \& Cognition, 15, 181-198.

WARREN, R. M., \& WARREN, R. P. A. (1966). A comparison of speech perception in childhood, maturity, and old age by means of the verbal transformation effect. Journal of Verbal Learning \& Verbal Behavior, 5, 142-146.

YIN, C., \& MACKAY, D. G. (1992, March). Auditory illusions and aging Transmission of priming in the verbal transformation paradigm Poster presented at the Cognitive Aging Conference, Atlanta.

(Manuscript received November 22, 1995 ; accepted for publication January 22, 1996.) 